\title{
When do investors prefer copycats? Conditions influencing the evaluation of innovative and imitative ventures
}

\author{
Yingzhu Fu ${ }^{1}$ | Matthias A. Tietz ${ }^{2}$ \\ ${ }^{1}$ Nanyang Business School, Singapore, Singapore \\ ${ }^{2}$ IE Business School, Madrid, Spain
}

\section{Correspondence}

Yingzhu Fu, Nanyang Business School,

50 Nanyang Avenue, Block S3, Singapore 639798, Singapore.

Email: yingzhu.fu@ntu.edu.sg

\begin{abstract}
Research Summary: This article investigates the conditions under which investors preferentially evaluate fast follower business model copycats (BMCs)-less novel, imitative ventures-over novel ventures. Employing a conjoint experiment, we find that venture investors prefer fast follower BMCs when the venture team has major capability advantages in exploitation (compared to exploration). Further, we find that investors' experience reduces their preference for fast follower BMCs when the team's capability advantage is in exploitation, and reduces their preference for novel ventures when the team is strong in exploration. These findings provide important theoretical and managerial implications.

Managerial Summary: Business model copycats represent a popular phenomenon in the global market. Fast follower BMCs are especially influential as many of them received millions of dollars of investment, and achieved billions of dollars in evaluations, both resulting in worldwide recognition. But although fast follower BMCs have the potential to conquer any market, they are not always highly valued by investors when initiating their businesses. We investigate when this is the case and find that team explorationexploitation capabilities influence investors' evaluation preference toward novel ventures and fast follower BMCs. If entrepreneurs are skilled in exploitation, creating a fast
\end{abstract}


follower $\mathrm{BMC}$ venture might be a great pitch to secure investment. Yet, if entrepreneurs are mostly competitive in exploration, creating fast follower BMCs does not attract investment easily.

\section{KEYWORDS}

business model copycat, conjoint experiment, exploration and exploitation, investor evaluation, novelty and uncertainty

\section{1 | INTRODUCTION}

Venture investors play a significant role in entrepreneurial ecosystems. Hence, entrepreneurship scholars show continuous interest in understanding venture investors' decision making, particularly in their evaluation of new ventures (Shepherd, 1999a; Warnick, Murnieks, McMullen, \& Brooks, 2018). Studies suggest venture investors place high emphasis on assessing the characteristics of both the venture team (Franke, Gruber, Harhoff, \& Henkel, 2008) and the business model (BM; Petty \& Gruber, 2011), which refers to the architecture describing what businesses do (e.g., products and services) and how they do it (e.g., organizational designs, processes, and activities; George \& Bock, 2011; Zott, Amit, \& Massa, 2011). One of the repeated key findings in the literature is that investors consistently seem to prefer ventures with innovative and pioneering BMs (Kollmann \& Kuckertz, 2010; Shepherd, 1999b; Shepherd, Ettenson, \& Crouch, 2000). Consequently, investors seek teams with high quality in characteristics such as technical education and new venture experience (Franke et al., 2008), which are likely to facilitate the introduction of new innovations and development of new markets.

However, the emerging phenomenon of business model copycats (BMCs)-ventures trying to pursue business opportunities by purposefully imitating leading BMs-raises new questions regarding the contingencies of investors' preference for more innovative ventures. Fast follower BMCs are especially influential. Fast imitation of innovations pioneered by leading firms allows for reducing uncertainty and learning from innovators' mistakes and can result in highly competitive rivals in the same markets (Boeker, 1989; Lieberman \& Asaba, 2006; Lieberman \& Montgomery, 1998). Fast follower BMCs increasingly represent a global phenomenon, as thousands of ventures aim to share or even conquer the market through imitation rather than innovation (Amit \& Zott, 2015; Zott \& Amit, 2007). Recent, well-known examples of fast follower BMCs include Lyft (follower of Uber in the United States), Mobike (follower of Ofo in China), and GrabFood (follower of Foodpanda in Singapore; Carson, 2017; Wei, 2018; Yang, 2018; Zaleski, 2017). These fast follower BMCs have successfully achieved millions of dollars of investment, billions of dollars in evaluations, and worldwide recognition. Entire startup accelerators, like Rocket Internet, now specialize in fast follower BMC development. Not surprisingly, well-funded fast follower BMCs have emerged alongside, and in some cases have even overtaken, initial first movers (Carson, 2017; Yang, 2018; Zaleski, 2017). In this research, we focus on investors' decision making regarding fast follower BMCs in comparison with novel ventures.

Venture investors typically receive a large number of business plans at once and must carefully evaluate and compare them before making their investment decision (Petty \& Gruber, 2011). Most ventures do not pass the initial screening (Kollmann \& Kuckertz, 2010). Fast follower BMCs increasingly attract investors, but the conditions under which investors prefer them over truly novel ventures are not well understood, representing an important theoretical limitation in the literature.

Moreover, fast follower BMCs do not fall neatly into existing theoretical frameworks. Thus, we lack a sufficient understanding of investors' considered high-level tradeoffs between higher novelty and lower uncertainty-specifically, the perceived aggregate environmental uncertainty in technology and market demand. The literature on 
investor decision making thus far has emphasized the independent effects of novelty and uncertainty (Li, 2008; Shepherd, 1999b). However, a recent development on uncertainty indicates that novelty and the level of uncertainty are interrelated (Packard, Clark, \& Klein, 2017). Entrepreneurial action occurs only when perceived uncertainty decreases to an acceptable level according to the subjective assessments and preferences of the entrepreneurial actors. Accordingly, we see the need to conceptualize novelty and uncertainty as competing parameters in investors' decision making. Specifically, building on the known tension between novelty and uncertainty in entrepreneurial activities (Freel, 2005; McMullen \& Shepherd, 2006; Packard et al., 2017), we develop theoretical arguments about the conditions under which investors consider novel ventures with high perceived uncertainty in technology and market demand (McKelvie, Haynie, \& Gustavsson, 2011) on the one hand, and less novel fast follower BMCs with less perceived uncertainty on the other.

We aim to develop and test an empirical model of the conditions under which investors would prefer fast follower BMCs over novel ventures in their evaluation. Underpinning this model, we first review the literature on strategic imitation (Lieberman \& Asaba, 2006) and elaborate on the tensions between novelty and uncertainty (McKelvie et al., 2011; Packard et al., 2017; Zott \& Amit, 2007), which relate to the unique strengths and weaknesses of novel ventures and fast follower BMCs. This allows for identifying team and BM characteristics associated with investors' preferences. We then argue that venture team exploration-exploitation capabilities and BM complexity are two key conditions that affect investors' evaluation of fast follower BMCs and novel ventures. Moreover, we know there is variance across individuals in their weighting of criteria when making decisions on a venture evaluation task (Shepherd, 2011). This is particularly due to differences in experience, which is associated with (a) the ability to understand the uncertain nature of the venturing process (Murnieks, Cardon, Sudek, White, \& Brooks, 2016); (b) the maturity of cognitive structures (schemata) used for predicting, explaining, and developing opinions (Franke et al., 2008); (c) the efficiency of the evaluation process (Shepherd, Zacharakis, \& Baron, 2003); and (d) confidence in decision processes (Zacharakis \& Shepherd, 2001). Given its central role in the investor decision-making literature, we therefore also investigate the influence of investors' experience on their evaluations of novel ventures and fast follower BMCs.

We employ a conjoint experiment design to test our hypotheses. Conjoint experiments serve as a suitable and preferable empirical method for investigating investors' evaluations of new ventures, especially when the research question concerns factors at both the decision and the individual level (De Rassenfosse \& Fischer, 2016; Gruber, Kim, \& Brinckmann, 2015; Murnieks et al., 2016; Shepherd \& Zacharakis, 1999; Warnick et al., 2018).

Our work aims to make three contributions to theory in entrepreneurship and investor decision making. First, we extend current theory on investor decision making by emphasizing the interrelationship between novelty and uncertainty, by integrating our study on conditions under which investors prefer fast follower BMCs over novel ventures with novel contributions on uncertainty transitions in the entrepreneurial process (Packard et al., 2017). This is important because the current theory tends to suggest that investors systematically prefer more innovative and pioneering ventures (Kollmann \& Kuckertz, 2010; Shepherd, 1999b; Shepherd et al., 2000). Consequently, current theory does not offer sufficient possibilities for developing a deeper understanding of investors' consideration of alternative venturing forms like fast follower BMCs. Thus, our work provides first evidence that investors' preference toward BMCs or novel ventures is contingent on team exploration-exploitation capabilities. We hope that our work will frame the discourse for future research on BMCs and encourage further investigation on contingencies affecting investors' consideration of venture innovativeness.

Second, we contribute by expanding the growing literature related to the influence of investor characteristics on the evaluation of new ventures. Many studies encourage future research to investigate how investors' and ventures' characteristics interact (Chan \& Park, 2015; Franke et al., 2008; Franke, Gruber, Harhoff, \& Henkel, 2006; Mitteness, Sudek, \& Cardon, 2012; Murnieks et al., 2016; Murnieks, Haynie, Wiltbank, \& Harting, 2011). A comprehensive understanding of these interactions is needed to make accurate predictions about individual decision making. We answer this call by examining whether differences in investors' experience might affect the importance assigned to team exploration-exploitation capabilities and BM complexity in the evaluation preference of fast follower BMCs or 
novel ventures. Our work offers novel insights into why some investors prefer fast follower BMCs over novel ventures, given certain team and BM characteristics.

Third, we also contribute to research on BMCs (Cliff, Jennings, \& Greenwood, 2006; Samuelsson \& Davidsson, 2009; Zott \& Amit, 2007). Although studies have made efforts to explore factors leading to the development and performance of BMCs, it remains unclear how BMCs are able to secure initial financial resources from investors to launch the business and survive the early launch stage. Thus, the current theory on BMCs is incomplete with regard to their initial performance in fundraising. Our work contributes in this area by investigating the team and BM characteristics influencing the initiation of BMCs, as these characteristics are fundamental to their later development. This sheds new light on the conditions under which BMCs are able to compete with novel ventures in securing investment.

\section{2 | FAST FOLLOWER BM COPYCATS}

A BM refers to the architecture describing what businesses do (e.g., products and services) and how they do it (e.g., organizational designs, processes, and activities) when creating value and serving market needs (George \& Bock, 2011; Zott et al., 2011). Regarding BMCs, we still lack a clear conceptual understanding (Cliff et al., 2006; Samuelsson \& Davidsson, 2009; Zott \& Amit, 2007). Thus, we conceptualize fast follower BMCs based on the few existing studies and the literature on imitation to derive our working definition.

First, entrepreneurs choose to imitate market pioneers when they conclude that these firms possess superior information regarding the potential market demand and technological trend (Lieberman \& Asaba, 2006). They are willing to sacrifice some novelty in exchange for less market and technology uncertainty. However, imitation is not worthwhile for late adopters, since market pioneers have already developed a dominant position in the market and there is limited space for BMCs to earn a decent profit (Suarez, Grodal, \& Gotsopoulos, 2015). Thus, fast follower BMCs seek to imitate only newly emerged leading BMs in order to avoid missing the window of opportunity.

Moreover, unlike necessity entrepreneurs who may start a similar business by chance, BMCs imitate actively so as to copy the success of a leading venture. In addition, rather than imitating only certain products of established firms (Lieberman \& Asaba, 2006), BMCs imitate entire BMs, including not only what is sold to whom and how. This purposeful imitation of both business offerings and processes sets BMCs apart from simple or partial imitations.

Second, unlike first movers, who create value through the conceptualization and adoption of new ways of conducting economic exchanges, fast follower BMCs do things similarly to pioneering firms to create value (Zott \& Amit, 2007). BMCs have a high level of market commonality and aim to seek and organize resources similarly to the copied market pioneers (Chen, 1996). Thus, compared with market pioneers, BMCs have high market commonality, high reliance on similar resources, high similarity in the organization of these resources, and relatively later entry timing. Consequently, fast follower BMCs are less innovative in their technology and how they address market demand compared to novel ventures, which conversely aim at introducing "new to the world" practices to create new markets, to innovate transaction processes in existing markets (Foss \& Saebi, 2017; Zott \& Huy, 2007), or both. Thus, novel and BMC ventures can be distinguished by whether the venture initially relies on the imitated BM (or its major components) for potential value creation (Winter \& Szulanski, 2001; Zott \& Huy, 2007). Although it is possible that a BMC's reliance on the imitated BM may change over time (Kim, 1997), we focus on the initial stage in which funding is sought, thus disregarding potential changes in the reliance on imitation over time and space.

Considering these two main characteristics-entire BM copying and early stage focus on leading BM imitationand based on the conceptual groundwork presented above, we define fast follower BMCs as entrepreneurial ventures that initiate their business through the fast and purposeful imitation of leading BMs and rely centrally on the imitated BM for value creation. At least in early venture stages, BMCs have high market commonality and high reliance on similar resources to copied market pioneers. Given these clear boundaries, it is fair to suggest that fast 
follower BMCs trade novelty for less environmental uncertainty in technology and market demand, although they do not lose novelty completely in the market.

Importantly, the speedy imitation of a leading BM does not guarantee success (Lieberman \& Asaba, 2006). Indeed, fast follower BMCs face enormous challenges in both the initial imitation and the later competition with market pioneers (Lieberman \& Asaba, 2006; Lieberman \& Montgomery, 1998). Imitation involves difficulties in decoding the secret of market pioneers' innovations, especially when such innovations are contingent on high complexity and tacit knowledge, therefore resulting in high causal ambiguity and inimitability (Lieberman \& Asaba, 2006; Rivkin, 2000). Consequently, many BMCs fail to secure investment, fail to survive, or struggle to grow. Even when imitating leading BMs, fast follower BMCs are not necessarily better investments than novel ventures. It is therefore necessary to consider the conditions under which less innovative ventures such as fast follower BMCs have the strength to attract initial investment.

\section{3 | UNCERTAINTY, NOVELTY, AND (DIS)ADVANTAGES OF FAST FOLLOWER BM COPYCATS}

Although challenges to success exist when pursuing imitation strategies and sacrificing innovativeness, such strategies can bring forward competitive ventures (Lieberman \& Asaba, 2006; Zott \& Amit, 2007) and thus attract venture investors. Specifically, we suggest that fast follower BMCs have advantages in lower perceived environmental (state and effect) uncertainty in technology and market demand, which are classic and impactful types of uncertainty that decision makers face in the entrepreneurial context (McKelvie et al., 2011). Conversely, their main disadvantage is that they compete with leading firms in the same market with the same BMs (Lieberman \& Montgomery, 1988, 1998). More importantly, given high market commonality and resource similarity, market pioneers are more likely to perceive imitation activities as competitive rivalry, especially in the case of local rival isomorphism (Miller, Indro, Richards, \& Chng, 2013), and respond with aggressive actions (Chen, 1996; Collis, 1991). This would cause investors to worry about the issue of competition.

In contrast, novel ventures aim to pursue opportunities by means of novel BMs, which create new markets (capture new market demands), innovate transaction processes in existing markets (offer new technologies; Zott \& Amit, 2007), or both. They have a better chance of achieving first-mover advantages as market pioneers (Lieberman \& Montgomery, 1988) and thus can attract investors through the potential of growth and profitability. However, there is uncertainty with regard to not only the existence and severity of problems that can potentially be solved (market demand uncertainty) but also the best methods to address these problems and the consequences of solutions (technology uncertainty; York \& Venkataraman, 2010). The new BMs originate in the condition of absolute uncertainty: the problem has an open set of possible solutions, each of which has an open set of outcomes (Packard et al., 2017). Even the option set regarding the problem itself is open. In such condition, investors still face important questions regarding the market demand, the effectiveness of the proposed solution, and so on. In short, while investors enjoy the newness and innovativeness of novel ventures, they typically perceive higher environmental (both state and effect) uncertainty in both market demand and technology.

Conversely, BMCs replicate the advanced structure, content, and governance of transactions between the existing focal firm and its exchange partners (Amit \& Zott, 2015; Zott \& Amit, 2007). BMCs adopt proven methods to capture known market demands with tested technology (Lieberman \& Asaba, 2006). As successful market pioneers verify market demand and demonstrate the plausibility of their technologies, BMCs can capitalize on a better-understood, better-prepared, and often presegmented and preeducated market. For investors, this means that perceived environmental (state and effect) uncertainty in both technology and market demand (e.g., the impact on new ventures of environmental changes leading to emerging demand patterns and technology development; McKelvie et al., 2011; Milliken, 1987) is largely reduced, although not fully resolved. The option set of both problems and solutions, as well as the outcome set of them close with the emergence of important information from leading firms' attempts 
(Packard et al., 2017). In other words, first movers' success indicates that the market demand is real, and their high growth indicates that it is sizable. Further, the positive market reaction to leading firms' offerings shows that the employed technologies inherent in their BMs are effective and welcomed by customers. Clearly, uncertainties are always present and cannot be fully resolved (Packard et al., 2017), and market demand and technology might still change over time. Nonetheless, evidence from market pioneers at least largely relieves investors' concerns pertaining to the perceived uncertainty in market demand and technology (Packard et al., 2017).

Despite the benefits of imitation, investors understand the tradeoff with the resulting direct competition between fast follower BMCs and leading firms. As BMCs are by default less novel than the imitated leading firms, a key for their success over incumbents in the market is to achieve better execution, resulting in higher efficiency, which often translates into lower operational costs (Ulhøi, 2012; Zott \& Amit, 2007). However, a pressing question pertains to the conditions under which BMCs are able to convince investors that they are capable of achieving better execution. Given that market pioneers might already have enjoyed first-mover advantages and developed strong execution capabilities (Zachary, Gianiodis, Payne, \& Markman, 2015), these conditions become exponentially important in investors' considerations.

Investors are further concerned by the fact that BMCs still face the internal liability of newness, the high risk of young organization failure (Wiklund, Baker, \& Shepherd, 2010) often linked to challenges in establishing reliable operation systems and accountable administrative processes (Choi \& Shepherd, 2005). While BMCs actually can enjoy a lower level of external liability of newness (i.e., the high risk of new organization failure due to the lack of creditworthiness and legitimacy from external stakeholders), since external stakeholders are already being educated by market pioneers (Wiklund et al., 2010), investors still emphasize BMCs' internal liability of newness due to the threat from those successful and established first movers. These issues would further amplify investors' concerns regarding the disadvantages of fast follower BMCs and lead to further requirements for venture teams' relevant capabilities to replicate the operational system and administrative processes efficiently.

Overall, the comparison between novel ventures and fast follower BMCs is not a simple comparison of novelty. Rather, it involves the consideration of both novelty and uncertainty. Given such complexity, it would be inaccurate to suggest that investors prefer novel ventures simply due to higher novelty or fast follower BMCs simply due to lower uncertainty. Thus, to answer our research question, it is important to explore contingencies, which enhance BMCs' advantages and moderate their disadvantages. Fast follower BMCs can gain funding and to be successful if they imitate effectively and efficiently, although it is not easy to orchestrate the BM and team to do so. Therefore, it is important to discuss team and BM characteristics that potentially shift investors' preference toward less novelty or less perceived uncertainty.

\section{4 | TEAM AND BM CHARACTERISTICS AFFECTING INVESTORS' EVALUATION}

Following the above discussion, we suggest that two factors are closely related to investors' consideration of the tradeoff between novelty and perceived uncertainty and thus their evaluation of fast follower BMCs versus novel ventures: team exploration-exploitation capabilities and BM complexity. We also suggest individual investor experience as a meaningful influence on investors' investment decisions regarding BMCs.

Team exploration-exploitation capabilities refer to the venture team's relative strength of exploration or exploitation capabilities (Gupta, Smith, \& Shalley, 2006; March, 1991). Empirical findings suggest that entrepreneurial team characteristics are of utmost importance in investors' evaluation of a venture (Kollmann \& Kuckertz, 2010). Ideally, investors seek teams that are strong in both exploration and exploitation, since the development and balance of these capabilities have important implications for firms' sustainable performance (He \& Wong, 2004). However, new ventures (like established firms) are often strong in only one or the other type of capabilities (Voss \& Voss, 2013). In practice, many venture teams aim to develop and launch novel practices but do not have advantages in exploration 
capabilities. Conversely, a venture team with strong exploration capabilities could choose to imitate rather than to innovate. Thus, the venture type (either novel or fast follower BMC) does not necessarily align with team capabilities (either exploration or exploitation), as they are independent of each other. We suggest investors would consider the fit between venture type and team exploration-exploitation capabilities in their evaluation.

Business model complexity refers to the amount and degree of multisided interactive components that require time and resources for BM development (Rivkin, 2000, 2001). First, BM complexity influences the challenges of achieving efficient execution and the internal liability of newness, since complex organizational structures and processes require extra effort for entrepreneurs to replicate the operational system and the administrative processes. High complexity makes it more difficult to establish reliable routines, delegate roles and tasks for team members, integrate different BM components, document rules, and allocate resources, since highly complex BMs are nondecomposable systems, in which the interactions among the subsystems are essential (Foss \& Saebi, 2017). Such complexity, once addressed, favors market pioneers who have already established their BMs. Second, complex BMs strengthen the advantages of first movers by prolonging their lead time in the market. This is because complex BMs are associated with higher causal ambiguity, which increases the difficulty for followers to effectively and efficiently imitate (Lieberman \& Asaba, 2006). Therefore, BM complexity is likely to influence investors' evaluation preference toward novel ventures and fast follower BMCs.

Individual investor experience refers to the amount of professional expertise an investor has acquired over years of involvement with venture financing. Research suggests that investors' experience might have a strong influence on how venture characteristics are evaluated (Franke et al., 2008; Shepherd et al., 2003). This is because investors accumulate experience to form and refine their cognitive structures (schemata), which process the information cues acquired for evaluating new ventures (Gagné \& Glaser, 1987; Spence \& Brucks, 1997).

Figure 1 presents our research model.

\section{5 | HYPOTHESES DEVELOPMENT}

\section{1 | Team exploration-exploitation capabilities}

Studies indicate that organizations have two key sets of capabilities-exploration and exploitation (Gupta et al., 2006; March, 1991). Exploration includes activities such as searching, discovery, innovation, and experimentation, while exploitation relates to refinement, efficiency, implementation, and execution (March, 1991). Based on this definition, we argue that exploration is predominantly relevant to technology development, while exploitation is predominantly related to management processes. The balance between exploration and exploitation has a major impact on organizational performance (Raisch, Birkinshaw, Probst, \& Tushman, 2009). However, firms' capabilities and skills are often more strongly developed in one area than the other, which makes it difficult to pursue both goals at the same

FIGURE 1 Research model. BMC, business model copycat

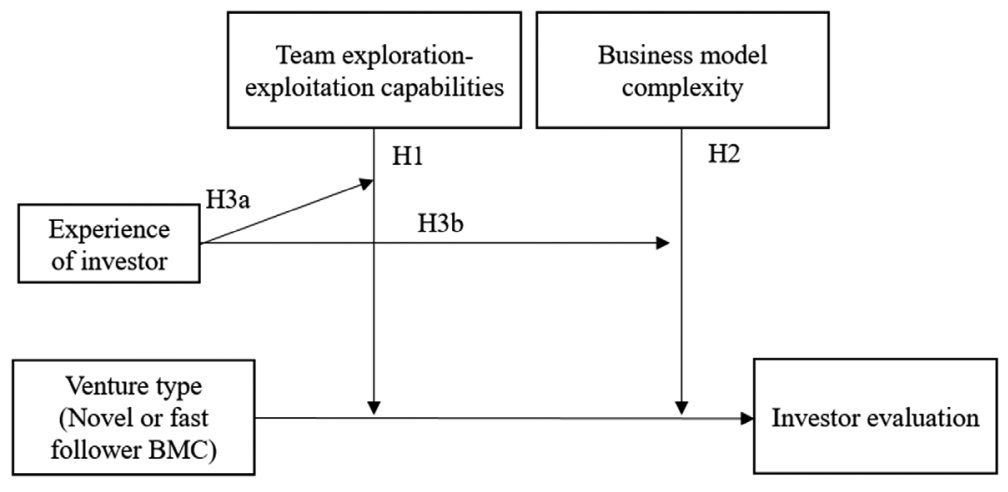


time (Gupta et al., 2006). This is particularly the case for new ventures that lack developed capabilities on their own and rely primarily on their core teams' preexisting capabilities and experience (Klotz, Hmieleski, Bradley, \& Busenitz, 2014; Voss \& Voss, 2013). Hence, with any specific venture team, the major team capability advantage rests primarily on either exploration or exploitation.

We argue that whether the major team capability advantage is in exploration or exploitation raises investors' concerns regarding challenges associated with different levels of novelty and uncertainty and thus affects their evaluation preferences. Since novel ventures and fast follower BMCs have distinctive strategic tasks and market conditions (Zott \& Amit, 2007), they rely on different sets of capabilities. Presumably, investors would prefer that a team aiming to create a novel venture be strong in exploration, which primarily contributes to the conceptualization and adoption of new ways of conducting economic exchanges. Conversely, if a team aiming to launch a novel venture is strong in exploitation, investors would be likely to doubt its ability. In other words, capability advantage in exploration grants entrepreneurs advantages in pursuing novelty and facing higher environmental uncertainty in technology and market demand. Existing evidence provides strong support that investors prefer a venture team with a strong engineering background when the BM involves novel technologies (Franke et al., 2008). In such cases, a team consisting of managers alone is clearly not viable, even if management capabilities strongly impact implementation efficiency (Chandler \& Hanks, 1994).

The task of fast follower BMCs, on the other hand, is to imitate existing innovations rather than to create new ones. In this context, exploitation capabilities are more important, as they make it possible to imitate effectively and efficiently. Exploration capabilities are less vital for fast follower BMCs, since information from leading firms reduces uncertainty and the sets of options and outcomes (Packard et al., 2017). Further, strong exploitation capabilities also help to combat the challenges of internal liability of newness by facilitating the implementation and refinement of existing means (March, 1991), such as the imitated operational system and administrative processes. With a major advantage in exploitation capabilities, BMCs are more likely to be able to accurately replicate or even enhanced the imitated elements, potentially achieving higher efficiency than first movers. Existing research indicates that investors seek teams with strong business and strong technical qualifications (Kollmann \& Kuckertz, 2010), since normally technology development and business execution are both critical for new ventures. However, given the imitative nature of BMCs, investors would likely place more value on business qualifications, which represent exploitation capabilities. Thus, if a team is strong in exploitation, investors should prefer for this team to create a fast follower BMC rather than a novel venture, as exploitation makes it possible to successfully implement and potentially even improve upon the copied BM, thus competing with or even replacing market pioneers (March, 1991). With a capability advantage in exploitation, fast follower BMCs' reduced novelty becomes ameliorated through the advantages of lower uncertainty.

We acknowledge that both exploration and exploitation are important for any venture to achieve long-term success (March, 1991). Thus, in the later stages of both BMCs and novel ventures, it is important to develop both capabilities. Initially, however, investors would want to see a good fit between a team's initial capability advantage and the type of venture it aims to create. Accordingly, if two teams with the same type of capability advantage (i.e., either exploration or exploitation) aim to create different types of ventures (i.e., BMC vs. novel venture), investors would prefer the team that shows capability-venture fit.

Hypothesis (H1). Venture investors are more likely to prefer less novel ventures such as fast follower BMCs over novel ventures in their evaluation when the venture team has major capability advantages in exploitation rather than exploration.

\section{2 | BM complexity}

Studies suggest that BMs can be conceptualized as "complex systems" involving interdependencies among the ventures' value creation, delivery, and capture mechanisms and the underlying activities (Foss \& Saebi, 2017). Rather than a simply linear mechanism for value creation, BMs often involve a complex, interconnected set of exchange 
relationships, and activities among multiple players (Zott et al., 2011). Given that different BMs represent different levels of complexity (Smith, Binns, \& Tushman, 2010), we argue that the level of BM complexity affects investors' evaluation preference toward novel or fast follower BMC ventures.

First, BM complexity amplifies the time and resource demand to establish the business architecture. Highly complex BMs are often composed of interdependent subsystems with clusters of activities that contribute to the general value creation, delivery, and appropriation mechanisms. This means that highly complex BMs require the development of multilayer, multiplayer structures to enable their implementation and value creation (Foss \& Saebi, 2017). Given the costs and time necessary to develop such complex BMs, investors would favor the use of these models in novel ventures, which can potentially better secure returns on such investment via a first-mover advantage (Lieberman \& Montgomery, 1988, 1998). Accordingly, empirical evidence shows that relatively more complex BMs such as innovative manufacturers and "IP landlords" (Weill, Malone, \& Apel, 2011), which require more time and effort for R\&D and business development, can be attractive for investors with longer time horizons. Fast follower $\mathrm{BMCs}$, on the other hand, would find it difficult to replicate highly complex BMs, especially when market pioneers have already occupied relevant resources or developed relevant capabilities. Importantly, according to evidence from research on investors in the dot-com bubble, investors investing into fast follower BMCs expect to quickly step into emerging areas, catch the new trend, and, if possible, achieve high multiples within a relatively short period (Valliere \& Peterson, 2004). Thus, investors' expectations might differ for novel ventures and fast follower BMCs, leading to different preferences regarding BM complexity.

Further, complex BMs entail factors driving the initial liability of newness. A BM is complex when its functioning relies on the dedicated integration of various organizational units and processes (Foss \& Saebi, 2017). In such cases, it is more costly for entrepreneurs to learn the internal organizational tasks, understand and delegate different organizational roles, discover the most effective and efficient ways of operating, and establish informal organizational structures to facilitate communication (Choi \& Shepherd, 2005).

On the other hand, if BM complexity is low, investors would prefer fast follower BMCs in their evaluation, since replication will be much easier, faster, and less costly than with high BM complexity. Most importantly, fast follower BMCs can piggyback or even freeride on the efforts expensed by the market pioneer (Casadesus-Masanell, 2013; Teece, 1986). Chances to benefit as a fast follower are great if uncertainty has already been reduced by the market pioneer, and low BM complexity readily affords access to relevant new market or technology insights. Hence, fast follower BMCs need less time than market pioneers to implement their BMs, can join the market more easily, and are typically able to avoid making costly mistakes. Low BM complexity also affords market pioneers less time to accumulate important resources and develop strong relationships and capabilities for competition. This renders fast follower BMCs even more likely to learn from, catch up to, and eventually surpass the BM of the market pioneer.

Second, BM complexity creates the opportunity to block imitators of novel ventures. As such, BM complexity represents an important constraint to successful imitation (Lieberman \& Asaba, 2006). In this context, scholarship suggests that venture investors put high emphasis on the protectability of novel BM components, such as products and services (MacMillan, Siegel, \& Narasimha, 1985; Maxwell, Jeffrey, \& Lévesque, 2011). Such protectability is increasingly difficult to achieve with "simple" BMs that would require only limited effort and time to be replicated (Lieberman \& Asaba, 2006). Thus, investors would favor novel ventures with the potential to develop novel and complex BMs that will be difficult for future competitors to imitate. Following the same logic, investors would also question the effectiveness of imitation if fast follower BMCs tried to imitate complex business structures involving tacit knowledge that only market pioneers possess. Consequently, BM complexity presents a challenge to effective imitation by BMCs. In contrast, if BM complexity were low, investors would have less confidence in a novel venture's ability to block future imitators, while at the same time investors should be more likely to trust the fast follower BMCs' capabilities of effective replication.

Hypothesis (H2). Venture investors are more likely to prefer less novel ventures such as fast follower BMCs over novel ventures in their evaluation when BM complexity is low rather than high. 


\section{3 | Individual investor experience}

Shepherd et al. (2003) argue that investors' experience has a major impact on their decision processes. Accordingly, investors' experience would moderate all the two-way interactions presented above.

As individuals accumulate experience with respect to a specific task, they tend to become increasingly efficient and utilize superior decision processes in that task (Shepherd et al., 2003). They learn to focus attention on key dimensions relevant to the final judgment of decision tasks (Chase \& Simon, 1973; Choo \& Trotman, 1991). Further, experienced individuals develop mature schemata and clearer views on how to draw on relevant concepts, connections, and procedures to analyze a decision problem (Adelson, 1981; Franke et al., 2008; Gobbo \& Chi, 1986). Thus, in the context of venture evaluation, experienced investors are more knowledgeable about the key elements they consider important, have a deeper understanding of the uncertain nature of the entrepreneurial journey, and employ a more comprehensive view in considering the advantages and disadvantages of different venture characteristics (Murnieks et al., 2016).

Accordingly, when experienced investors assess team exploration-exploitation capabilities, they assess the tradeoffs between these capabilities more comprehensively. Although fast follower BMCs and novel ventures differ in their strategic tasks and thus rely on different capabilities in the initial stage, experienced investors adopt a longterm view that recognizes that the success of any venture depends not only on a successful initiation but also on lasting capabilities to design ongoing innovation and improve execution (Zott \& Amit, 2007). In other words, more experienced investors are more likely to understand the importance of the balance between exploration and exploitation and thus to place more emphasis on the importance of having both competencies.

Similarly, experienced investors also have a deeper appreciation of the advantages and disadvantages of using BMs with different levels of complexity. Although it is generally risky for a BMC venture to pursue a complex BM, as it is more difficult to imitate effectively and efficiently, experienced investors are more likely to consider the possibility that if a BMC is able to imitate a complex BM successfully, it might also have competitive advantages over other potential imitators. Likewise, although the creation of a complex BM might enable novel ventures to block imitators, experienced investors would also consider the possibility of wasting important resources in exploring a complex BM, since the technology and market preferences might change with the development of the new market (Suarez et al., 2015).

Hypothesis (H3a). Investor experience reduces investors' evaluation preference (a) toward less novel ventures, such as fast follower BMCs, when the major team capability is exploitation rather than exploration and (b) toward novel ventures when the major team capability is exploration rather than exploitation.

Hypothesis (H3b). Investor experience reduces investors' evaluation preference (a) toward less novel ventures, such as fast follower BMCs, when BM complexity is low rather than high and (b) toward novel ventures when BM complexity is high rather than low.

\section{6 | METHOD}

\section{1 | Conjoint analysis}

This study uses a conjoint experiment. This technique requires respondents to make a series of decisions based on a set of attributes from which the underlying structure of their decisions can be decomposed by means of hierarchical regression and hierarchical linear modeling (HLM; Lohrke, Holloway, \& Woolley, 2010; Shepherd \& Zacharakis, 1999). A conjoint experiment is particularly well suited for our investigation of the relative influence of different 
decision factors on individual decision making. Compared with a traditional survey approach, the unique strength of a conjoint experiment is that all independent variables are set as attributes by the researchers, who then collect respondent ratings (dependent variables) based on different attribute combinations of the independent variables (Lohrke et al., 2010).

For metric conjoint analysis, the experimental design is typically orthogonal (i.e., there is zero correlation between attributes). Conjoint analysis is a well-established method for studying decision making and has been employed in many entrepreneurship studies for investigating investors (Lohrke et al., 2010; Shepherd \& Zacharakis, 1999). The major advantage of this method is that it captures venture investors' decision policies while they are "in use," thus overcoming many of the limitations associated with post hoc techniques that require introspection (Wood, McKelvie, \& Haynie, 2014).

In our study, we asked professional venture investors to assess a series of hypothetical investment opportunities and indicate their evaluation of the respective investment opportunity using a three-item measure. Following previous research using conjoint analysis (Shepherd, Patzelt, \& Baron, 2013), our investigation involves variables at three levels: the decision level (Level 1), the level of the manipulated contexts (Level 2), and the individual level (Level 3). Each opportunity profile conveys information about the evaluation contexts (Level 2, venture types), as well as attributes of the venture, including team exploration-exploitation capabilities, BM complexity, and BM disruptiveness (Level 1). We also captured respondents' level of investment experience through a postexperiment questionnaire (Level 3). As such, we are able to test the hypothesized cross-level interactions included in our hypotheses.

\section{2 | Sample}

Participants in this study were professional venture investors identified from a Chinese platform company that serves to organize entrepreneurial events and to connect investors with new venture projects. The platform company is located in Hangzhou and has branches in northern and southern China. The Hangzhou area is famous for its leading position in innovation and entrepreneurship and is ranked first in China regarding the growth rate of venture projects (Bai, 2018). The platform also has a notable connection with investors involved in a large number of unicorn ventures such as Alibaba Cloud, Cainiao Network, Caocao, Ant Financial, and others. We selected Chinese investors for two reasons. First, China currently has one of the most dynamic entrepreneurship environments with a large number of new ventures, many of which quickly adopt best practices from other jurisdictions. Thus, investors are familiar with and knowledgeable about the evaluation of both fast follower BMCs and novel ventures. Second, Chinese investors represent real and experienced investment decision makers.

To address this sampling frame, we first conceptualized, elaborated, and drafted the online conjoint experiment and survey in English. We then solicited feedback from entrepreneurship colleagues to hone its precision. Afterward, a native Chinese speaker translated the survey into Chinese. Then a second independent native Chinese speaker translated the Chinese version of the survey back to English, testing whether the conventional method of backtranslation (Brislin, 1970) rendered the same instrument. Following the back-translation, neither the concepts nor any broad meaning was changed, and the instrument still adequately represented the intent of the study.

Through a cell phone social network application (which is used more commonly than email for business communication in China), we sent participation requests to all 117 venture investors of 67 investment companies for which the platform listed contact data. The founder of the platform company endorsed and supported our research effort, as did some initially contacted friendly investors who helped us test, pilot, and fine-tune the wording of the conjoint study. We received 50 complete surveys, for a response rate of $42.7 \%$. While this sample size may appear small for demanding empirical analysis, a lack of sufficient data is not a concern in our study given that each respondent provided multiple evaluations. Indeed, our sample size is comparable with recent conjoint analysis research on investor decision making, such as the work of Murnieks et al. (2016), which had 53 completed surveys.

Our sample consisted of 43 male and only 7 female respondents. This gender imbalance is unfortunately unsurprising, as it still represents the reality in most investment-related roles in the traditionally male-dominated Chinese 
investor context. Participants ranged in age from 26 to 41 years, with a mean age of 31.82. On average, they had 3.86 years of experience as venture investors. In terms of education level, $36 \%$ held a bachelor's degree, $42 \%$ held a master's degree, and the remaining $22 \%$ held a doctoral degree. Following recommendations for testing nonresponse bias (Dooley \& Lindner, 2003), we employed a simple analysis of variance to test for differences between early and late respondents in terms of age, education, and experience. Results demonstrated no significant differences $(p>.1)$.

\section{3 | Research instrument}

We designed our research instrument following a number of published conjoint studies in entrepreneurship (Haynie, Shepherd, \& McMullen, 2009; Shepherd et al., 2013; Warnick et al., 2018; Wood et al., 2014). The research instrument consisted of three major components: (a) a task introduction and variable descriptions; (b) a series of conjoint profiles; and (c) a postexperiment survey.

In the task introduction and variable descriptions, we provided detailed explanations for the decision-making task, each of the manipulated contexts (venture types), and each of the variables used in the conjoint experiment. To provide a common context for participants (Haynie et al., 2009; Shepherd et al., 2013), in the task introduction we followed established practice and asked participants to make the following five assumptions before making their assessments: (a) "You are interested in potential investment within the next 12 months"; (b) "you have sufficient capital to invest"; (c) "you are making evaluations in the context of your current business environment"; (d) "each case is a separate situation, independent of all others"; and (e) "apart from the venture types and conditions we specify, all else is equal for each case."

In the conjoint experiment section, we asked venture investors to evaluate a series of hypothetical attribute profiles in each of the manipulated contexts. In each profile, three BM attributes are represented by one of two possible levels. Each of the eight $\left(2^{3}\right)$ possible profile combinations shows a different combination of attribute levels. The profiles are by design orthogonal, and there is zero correlation between attributes.

Since experimental designs typically include a test-retest reliability check that doubles the number of assessments for each participant, we followed common practice and used an orthogonal fractional factorial design to reduce the number of different attribute level combinations (Green \& Srinivasan, 1990). Hence, not all possible attribute level combinations were presented (Shepherd et al., 2013), and our investors evaluated eight profiles (four original profiles and four replications) in each of the two manipulated contexts. As a result, each of the 50 professional investors provided 16 evaluations, resulting in 800 evaluations by real investors. We use only the data from the original profiles for our empirical testing, although using the replication profiles renders essentially the same results.

Before large-scale data collection, we conducted a pilot test of the instrument and related interviews with three investors to ensure face validity, clarity of variable descriptions to the participants, and the manageability of the survey regarding the use of time. We improved the language and flow of the survey using input from these participants. To check face validity, in the interviews we asked the investors questions including whether they considered the attributes in our profiles in real investment decision making; whether the concepts, the explanation of these attributes, and the manipulated contexts (venture types) were clear to them; whether the levels of attributes were different and were clear to them; and whether they understood the decision-making tasks in the experiment. Respondents provided positive answers validating the instrument. In particular, the core concept of fast follower BMCs was clear to them immediately, since all of them had already evaluated dozens of fast follower BMCs and invested into several. Respondents suggested only minor changes to wording, which we adopted.

To ensure full understanding of the pilot and the actual survey, we showed participants a practice profile before they started the actual conjoint experiment. To control the potential order effect, we randomized the order of profiles and the order of manipulated contexts. Venture investors then evaluated the profiles and, based on the combination of attribute levels for each profile in each manipulated context, rated our dependent variable of investment potential. 


\subsection{Dependent variable}

We used a three-item measure designed by Murnieks et al. (2011) to capture the likelihood that the venture investors would evaluate the proposed venture project positively and would subsequently invest in it. The scale consisted of three items: (a) the probability that the investors would invest in the venture project, (b) the amount of money the investors would be likely to invest, and (c) how successful the investors thought the venture project would be. We asked participants to indicate their evaluation on a continuous scale from 0 to 100 anchored by "Low" and "High." Cronbach's Alpha of the three items was 0.93 , indicating strong internal consistency and high reliability of the measure. The mean of these three items serves as our dependent variable in our empirical tests (Murnieks et al., 2011).

\section{5 | Explanatory variables: Independent, control, and moderator}

\subsection{1 | Level 1: Decision-level explanatory variables}

Consistent with our theory and hypotheses, team exploration-exploitation capabilities and BM complexity served as the independent variables at the decision level. These variables are both designed and operationalized as binary archetypes and are described in detail in Table 1 below. Our operationalization of exploration and exploitation is consistent with the definitions introduced by March (1991).

Further, we know that investors place high emphasis on the general disruptiveness of a BM in the market. It is also possible for a fast follower's BM, though less disruptive than the copied leading firm, to be more disruptive than a different novel venture's new BM. Investors would consider this possibility in their evaluation. Thus, we control the effect of general BM disruptiveness.

\subsection{2 | Level 2: Manipulated contexts}

Our research focus is to investigate investors' evaluation preference toward novel or fast follower BMC ventures. The following descriptions were presented to the respondents to indicate the type of venture:

1. Novel venture with a "new-to-the-world" BM. The BM is novel, and the market is not developed. The uncertainty for technology and market demand are both high.

TABLE 1 Operationalization of independent variables (attributes)

\begin{tabular}{|c|c|}
\hline Variables & Levels \\
\hline $\begin{array}{l}\text { Team } \\
\text { exploration-exploitation } \\
\text { capabilities }\end{array}$ & $\begin{array}{l}\text { Exploration (coded as 1): The team has its core competence in discovering and creating } \\
\text { new practices (i.e., search for new things, experiment, discover new products/ } \\
\text { markets/channels) } \\
\text { Exploitation (coded as 0): The team has its core competence in improving existing } \\
\text { practices (i.e., refine existing things, improve efficiency, and manage existing } \\
\text { products/markets/distribution channels) }\end{array}$ \\
\hline Business model complexity & $\begin{array}{l}\text { High (coded as 1): The business model is complex and needs high investment of time } \\
\text { and resources for its development } \\
\text { Low (coded as 0): The business model is simple and needs low investment of time and } \\
\text { resources for its development }\end{array}$ \\
\hline $\begin{array}{l}\text { Business model } \\
\text { disruptiveness (control) }\end{array}$ & $\begin{array}{l}\text { High (coded as 1): The business model changes a lot of traditional business norms and } \\
\text { customer habits } \\
\text { Low (coded as 0): The business model changes few traditional business norms and } \\
\text { customer habits }\end{array}$ \\
\hline
\end{tabular}


2. Fast follower BMC that copies a BM from a very successful leading firm in the market. It targets the same market as the leading firm. The BM is not pioneering, and the market has been developed by the leading firm. The uncertainty for technology and market demand are both low.

\subsection{3 | Level 3: Individual-level variables}

We measured our moderator, investor experience, as the number of years that the respondent worked as a venture investor prior to the study. Studies further suggest that respondents' gender, education, and age are likely to influence their decision making (Mitchell \& Shepherd, 2010; Murnieks et al., 2011; Wood et al., 2014). Thus, our postexperiment survey captured information related to these control variables.

\section{ANALYSIS AND RESULTS}

The main study provided 800 total observations (16 observations per participant for 50 participants). The mean test-retest correlation for the dependent variable was 0.86. This indicates high consistency in investors' decision making. Further, we conducted paired sample $t$-tests based on the assumption that if investors provided reliable responses and understood our manipulation of attributes and contexts, there would be no significant difference between the average responses for the original profiles versus those for the replicated ones (Green \& Srinivasan, 1990). The means for our DV for the original profile compared to the repeat profiles were 36.89 versus 35.83 . This difference is not significant $(T=1.133, p=.26)$. These findings suggest reliable responses from our participants. Their consistency also provides evidence that investors understood the attributes, attribute levels, and manipulated contexts in the experiment.

In Table 2, we report the means, SDs, and correlations of the individual-level variables. Variables at other levels are orthogonally set by researchers in the experiment; they have zero correlation with individual-level variables and with each other. To check for multicollinearity, we tested the variance inflation factors (VIFs) and conditions statistics. All VIFs were below 1.6, and the conditions statistics were below 22.0. Both are below their respective generally accepted limits of 10 (Nachtsheim, Neter, Kutner, \& Wasserman, 2004) and 30 (Belsley, Kuh, \& Welsch, 2005).

As our study involves data at three different levels-(a) evaluations nested in (b) manipulated contexts nested in (c) individual investors-it is appropriate to use HLM to conduct the analysis. As the standard analysis method used in conjoint experiment studies (Lohrke et al., 2010), HLM enables us to deal with nested data. HLM captures investors' decision making at the decision level (Level 1), how the decision making varies across manipulated contexts (Level 2), and how the manipulated context's impact on the decision making is affected by individual-level variables (Level 3). To test our hypotheses, we use the original 400 evaluations. Thus, data from the replicated profiles are not used in our model. The intraclass correlation was $28 \%$, indicating that roughly $28 \%$ of the variance in investment evaluation was due to differences between participants. This is relevant for investigating cross-level hypotheses ( $\mathrm{H} 3 \mathrm{a}$ and $\mathrm{H3b}$ ) that predict individual differences in evaluation across investors. Table 3 shows the results of the HLM analysis. We follow the conventions established in numerous other studies using orthogonal fractional factorial designs for metric conjoint analysis (Haynie et al., 2009; Murnieks et al., 2016; Warnick et al., 2018; Wood et al.,

\begin{tabular}{lllllll} 
Variables & Mean & SD & $\mathbf{1}$ & $\mathbf{2}$ & $\mathbf{3}$ & 4 \\
1. Age & 31.82 & 4.20 & 1 & & & \\
2. Gender & 0.86 & 0.35 & -0.06 & 1 & & \\
3. Education & 4.86 & 0.76 & $0.52^{* * *}$ & $-0.31^{*}$ & 1 & \\
4. Experience & 3.86 & 2.89 & $0.30 *$ & -0.08 & 0.25 & 1 \\
\hline
\end{tabular}

TABLE 2 Descriptive statistics and correlations

$* p<.05 ; * * p<.01 ; * * * p<.001$. 
TABLE 3 HLM model of investor evaluation with robust standard errors

\begin{tabular}{|c|c|c|}
\hline Variables & Coefficient & SE \\
\hline Intercept for overall model & 19.355 & 13.254 \\
\hline \multicolumn{3}{|l|}{ Main effects } \\
\hline Intercept for the fast follower BMC & 4.294 & 3.216 \\
\hline Team exploration-exploitation capabilities & $6.717^{* * *}$ & 2.034 \\
\hline BM complexity & -1.296 & 1.709 \\
\hline BM disruptiveness & $14.223^{* * *}$ & 1.892 \\
\hline Experience & 0.277 & 0.565 \\
\hline \multicolumn{3}{|l|}{ Interactions (level $1 \times$ level 2 ) } \\
\hline Fast follower $\times$ team exploration-exploitation capabilities $(\mathrm{H} 1)$. & $-13.872^{* * *}$ & 3.364 \\
\hline Fast follower $\times$ BM complexity $(\mathrm{H} 2)$. & -2.125 & 3.299 \\
\hline \multicolumn{3}{|l|}{ Interactions (level $1 \times$ level $2 \times$ level 3 ) } \\
\hline Fast follower $\times$ team exploration-exploitation capabilities $\times$ experience (H3a). & $2.011^{* * *}$ & 0.614 \\
\hline Fast follower $\times$ BM complexity $\times$ experience $(\mathrm{H} 3 \mathrm{~b})$. & -0.114 & 0.468 \\
\hline \multicolumn{3}{|l|}{ Controls: age, gender, education } \\
\hline Wald chi ${ }^{2}$ & $77.12^{* * *}$ & \\
\hline Prob $>\mathrm{chi}^{2}$ & 0.00 & \\
\hline$R$-squared & $24 \%$ & \\
\hline Akaike information criterion (AIC) & $3,435.23$ & \\
\hline
\end{tabular}

Note: Number of obs: 400, number of groups: 50, obs per group: 8 .

Abbreviations: BMC, business model copycat; HLM, hierarchical linear modeling.

$* p<.05 ; * * p<.01 ; * * * p<.001$.

2014) and report only the full model. The analysis of both main effects and full models is neither necessary nor appropriate in this case, since the orthogonal research design assures there is zero correlation between criteria (Haynie et al., 2009).

In our model, we control all the main effects of our variables on investors' evaluation. Importantly, the intercept for the context of fast follower is not significant. This indicates that, on average, investors' evaluations for the fast follower are not significantly different from those for the novel venture. Thus, the type of venture (fast follower or novel) seems, in and of itself, to have no significant influence on investors' evaluation. Team exploration-exploitation capabilities $(\beta=-13.872, p<.001)$ show a negative and significant interaction with the context of fast follower. The effect size of this interaction is $3.4 \%$. As we coded team major capabilities in exploration as 1 and in exploitation as 0 , this significant negative interaction shows that team major capabilities in exploration (as compared to exploitation) weaken the influence of the fast follower context on investors' evaluation. Since on average the evaluation of fast follower BMCs is not significantly higher or lower than that of novel ventures (i.e., the main effect of the intercept of the fast follower context is not significant), this significant interaction effect shows that investors' evaluations are lower (higher) for fast follower BMCs than for novel ventures when team major capabilities are in exploration (exploitation), as shown in Figure 2. Thus, our data support $\mathrm{H} 1$, while $\mathrm{H} 2$ is not supported.

The three-way interaction between team exploration-exploitation capabilities, the context of fast follower, and investors' experience is positive and significant $(\beta=2.011, p<.001)$; the effect size is $2.6 \%$. This finding indicates that experience reduces the negative impact of team major capabilities in exploration (as compared to exploitation) on the influence of the context of fast follower on investors' evaluation. Specifically, the evaluation preference toward fast follower BMCs over novel ventures is (a) strongest when investors are inexperienced and the team major 


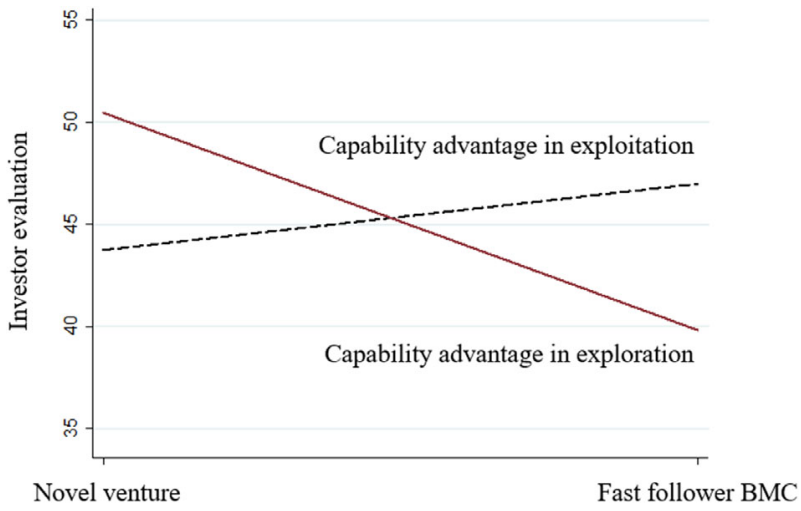

FIGURE 2 Interaction effect between venture type and team explorationexploitation capabilities. BMC, business model copycat

capabilities are in exploitation, (b) next strongest when investors are experienced and the team major capabilities are in exploitation, (c) weaker when investors are experienced and the team major capabilities are in exploration, and (d) weakest when investors are inexperienced and the team major capabilities are in exploration. Thus, H3a. is supported, while H3b. is not supported.

\section{8 | DISCUSSION}

The literature on investors' decision making suggests that novelty and lead time in the market are key factors for new ventures to achieve high evaluations (Kollmann \& Kuckertz, 2010; Shepherd, 1999b; Shepherd et al., 2000). Certainly, innovativeness is important for new ventures to receive venture investment, since ventures with pioneering practices can present promising investment opportunities, representing potentially extraordinary returns commensurate with the risk their novel character entails. However, highly novel practices typically originate in conditions of absolute uncertainty, which restrains entrepreneurial actions until sufficiently resolved. This is the case because both the option and outcome sets are open, leading to an unknown and open set of investment outcomes that is difficult to act upon (Packard et al., 2017). Despite record levels of investments into fast follower BMCs, the existing literature remains rather ambiguous about the conditions under which investors would prefer BMCs, which are clearly less innovative and enter the market later, over novel ventures. Inspired by the rising phenomenon of fast follower BMCs, we look at investors' evaluations of novel and fast follower BMC ventures and especially consider the tradeoff between novelty and less perceived aggregate environmental uncertainty in technology and market demand. This is of theoretical interest, because innovativeness and uncertainty are interrelated rather than simply independent characteristics of new ventures (Freel, 2005; McMullen \& Shepherd, 2006; Packard et al., 2017), and we highlight the key conditions under which investors allow one to prevail over the other.

We argue that investors leverage the unique combination of novelty with perceived aggregate environmental uncertainty, consider the tradeoffs of pursuing pioneering ventures, and estimate the unique benefits of investing into fast follower BMCs. Our test results show that the main effect of the context of fast follower BMCs is not significant. Although we cannot draw a conclusion from insignificant results, the lack of a significant finding nevertheless suggests that fast follower BMCs are not in and of themselves either more or less attractive to investors than novel ventures. Our finding thus seems to challenge some of the existing literature, which suggests a premium of novelty (Shepherd, 1999b; Shepherd et al., 2000). Indeed, this seemingly counterintuitive insight is consistent with our argument that the comparison between novel ventures and fast follower BMCs is not based solely on novelty. Instead, investors consider the advantages and disadvantages of both novel ventures and fast follower BMCs. Further, the insignificant main effect of venture types is actually in line with findings in the entry timing literature indicating that the fulfillment of first-mover advantages is contingent on contextual factors, and followers do have a 
chance to outperform pioneers (Lieberman \& Asaba, 2006; Suarez \& Lanzolla, 2007). It is also important to emphasize that the type of BMCs we operationalize and test are fast follower BMCs rather than later adopters, which rarely can offer any novelty.

Our findings then indicate that investors prefer fast follower BMCs over novel ventures when venture characteristics strengthen the advantages of fast follower BMCs while mitigating issues of reduced novelty. We find that (a) team exploration-exploitation capabilities are associated with investors' evaluation preference, and (b) this is further contingent on investors' individual level of experience. From the competition perspective, our findings show that to compete under the condition of high market commonality and resource similarity, fast follower BMCs need to have strong capabilities in exploitation to convince venture investors. By demonstrating the attractiveness of fast follower BMCs for investors, we provide insights on a new direction in which to explore investors' decision making.

\section{1 | Theoretical implications}

Our findings provide several implications for scholarship. First, our work provides strong and novel evidence that investors prefer less novel ventures such as fast follower BMCs over novel ventures when the venture team's major capabilities are in exploitation rather than exploration. We can understand the significant interaction effect between team exploration-exploitation capabilities and venture type on investors' evaluation from two perspectives. First, if a fast follower BMC and a novel venture both have their major capabilities in exploitation, investors would prefer to invest in the former. Second, when a team has major capability advantage in exploitation, investors are more likely to invest if this team aims to launch a fast follower BMC venture rather than a novel venture. As such, and in contrast to the prevailing assumption in the current literature (Kollmann \& Kuckertz, 2010; Shepherd, 1999b; Shepherd et al., 2000), we show that investors do not always favor ventures trying to introduce the most innovative or pioneering practices into the market. Rather, investors consider the specific team characteristics of the venture under evaluation and estimate the advantages and disadvantages of its venture type. This also raises further questions about whether the previously identified positive influence of innovativeness on investors' evaluation would be contingent on other potential factors. As such, studies on investors' evaluation of venture innovativeness and on the lead time in pioneering (Shepherd et al., 2000), might need to consider the potential tradeoffs of achieving higher innovativeness with longer lead time, as well as how team characteristics might affect these tradeoffs.

Our work is consistent with the understanding that investors place high emphasis on evaluating both uncertainty and novelty (Li, 2008; Shepherd, 1999b). However, our work offers the additional new insight that research should not simply treat uncertainty and novelty as independent decision criteria of venture investors. Our findings here are consistent with the uncertainty transition model, which predicts that the outcome of entrepreneurial actions depends on the nature of uncertainty at hand (Packard et al., 2017). Entrepreneurial actors would thus decide to wait or search for more information in order to close the option set and outcome set, even if they lose novelty in the process. Given our novel context, our findings offer potential opportunities to further extend and develop this model. We show that not only direct information, such as market demand and technology information, but also factors contextualizing this relationship can facilitate uncertainty transition and therefore lead to entrepreneurial actions. That means, even if the true option and outcome sets are still open (i.e., the true uncertainty is still high), entrepreneurial actors would perceive them as closing when contextual factors help resolve uncertainty.

The venture team's exploration-exploitation capabilities present one such uncertainty-resolving factor that contextualizes the Packard and his colleagues' model in our study. For instance, when a team has highly developed exploration capabilities, investors might expect that the option and outcome sets are closing more quickly. Even in the absence of more direct information about the market and technology, the effects we introduce here (e.g., team exploration capabilities), change investors' expectations (how the team can resolve uncertainty issues), and thus (positively) impact investors' evaluation. This inspires us to further explore other external factors influencing uncertainty transition, such as the available resources and regulatory contexts. 
Second, our work contributes to addressing the concern of scholars that the extant knowledge on investors' evaluation of team characteristics is still rather general and focuses primarily on the level of team quality (Franke et al., 2008; Muzyka, Birley, \& Leleux, 1996). We argue that, as new ventures often lack resources and capabilities, investors consider not only the level of quality but also the specific team exploration-exploitation capabilities. Team major capabilities in operating and improving existing BMs might not be ideal for novel ventures, whereas these capabilities would be more important than innovation skills for fast follower BMCs. Thus, even a high-quality team would fail to achieve high investor evaluation if it aimed to create the "wrong" type of venture (i.e., mismatching the team's exploration-exploitation capabilities and venture type).

Third, we contribute by expanding the venture investment literature surrounding the influence of individual investor characteristics on evaluations of venture team characteristics (Chan \& Park, 2015; Franke et al., 2006; Mitteness et al., 2012; Murnieks et al., 2011, 2016). Our work shows that individual experience reduces the likelihood that investors will prefer fast follower BMCs (novel ventures) when the team major capabilities are in exploitation (exploration). This finding, in turn, suggests that as investor experience grows, investors increasingly tend to consider exploration and exploitation as approaching equal importance for both $\mathrm{BMC}$ and novel ventures.

Our work is consistent with previous findings indicating that the effects of team characteristics are contingent on investors' experience (Murnieks et al., 2016). However, previous research suggests that experienced investors tend to put more weight on certain team characteristics over others in their evaluation (Franke et al., 2008) and that experience strengthens the influence of positive characteristics of entrepreneurs on investors' evaluation (Murnieks et al., 2016). However, our work also provides novel insights, as we show that experienced investors put less emphasis on only the most important capabilities relevant to the venture's strategic task at hand. Experienced investors instead tend to seek a more balanced combination of capabilities and to consider these capabilities from a futureoriented perspective. Thus, we encourage future research on investors' evaluation to consider investors' choice of different types of important team characteristics.

\section{2 | Managerial implications}

Our work has implications for practitioners, as we provide insights useful for fundraising for both novel and fast follower BMC ventures. First, our work highlights the importance of considering team exploration-exploitation capabilities when approaching venture investors. If entrepreneurs are mostly competitive in their skills of exploitation, creating a fast follower BMC venture might be a better option to secure investment. Given such a capability advantage, an overemphasis on creating novel practices might not be the best way to create profitable ventures and reach high growth. Imitation should also be understood as a viable, equally good strategy for entrepreneurs to attract venture investment and achieve entrepreneurial success. Accordingly, if entrepreneurs are mostly competitive in exploration, creating fast follower BMCs becomes a worse strategy for reaching their full potential of attracting venture investment. Entrepreneurs even need to change their team members to increase capabilities of exploitation and convince investors they can imitate properly. Finally, compared with more experienced investors, less experienced investors are more likely to consider the initial fit between venture type and team capabilities. Thus, if entrepreneurs with clear major capabilities of either exploration or exploitation aim to create a suitable type of venture, inexperienced investors are more likely to favor their clear major capabilities.

\section{3 | Limitations and future research}

As with all studies, there are certain limitations in our work. First, as we employed a conjoint experiment, it is possible that the results obtained may not necessarily fully reflect investors' actual decision making. Though designed to resemble reality as close as possible, the conjoint setting remains an artificial situation. While we acknowledge this limitation, the use of a conjoint experiment also has several important advantages: (a) judgments are made in a relatively controlled environment, (b) they are observed in real time and are thus not subject to hindsight bias and other 
retrospective reporting biases, and (c) it is possible to establish causal relationships between the stimulus provided (i.e., the profiles) and judgment outcomes (Shepherd et al., 2013, p. 1267). We also encourage future research to investigate investors' preference using other empirical methods, such as analyzing secondary data or conducting field experiments. For example, archival data on venture investors' competition analysis would provide interesting insights on factors leading to the evaluation differences regarding novel and fast follower BMCs. Researchers can also conduct field experiments (e.g., a business plan competition with a treatment group of fast follower BMCs and a control group of novel ventures) to investigate investors' evaluation of opportunity feasibility and desirability. Further, our theory building might also benefit from a qualitative study with in-depth interview data to understand the differences and nuances of the venture evaluation processes governing investments into novel and BMC ventures.

Second, our theory building focuses on the influence of perceived aggregate environmental uncertainty in technology and market demand, since we argue that fast follower BMCs are perceived to be less uncertain than novel ventures in both market demand and technology. This is consistent with the suggestion that new ventures are typically associated with absolute uncertainty (Packard et al., 2017). Although such a focus on the higher level of uncertainty is appropriate given our general research question, it would also be interesting to further unpack the uncertainty construct and investigate whether different types of BMCs with different types of uncertainty have different impacts on investors' preferences. While the current study is unable to investigate this question, in future research we would like to explore different types of BMCs, which are linked with different types of uncertainty, in investors' evaluations.

Third, although our experiment is designed to indirectly control for other influencing factors by asking respondents to make explicit assumptions and consider all else equal for each profile before making the evaluation, we are unable to directly test how other possible variables impact the investors' decisions. For example, the overall market volume and the current market share occupied by the leading firms would influence investors' evaluation of fast follower BMCs, since BMCs will have limited success if the first-mover advantages of leading firms are too overwhelming. Such types of challenges might be connected to industry attributes such as technology turbulence and resource dependence. Further, our research is unable to track whether the real decisions to invest in fast follower BMCs are motivated by a desire to "catch the gravy train" or to compensate from having previously missed out on similar opportunities (e.g., the initial first mover). Similarly, reputational effects can be influential to investors' evaluation of fast follower BMCs (Janney \& Folta, 2003). Thus, in future research, we would like to explore additional important individual, firm, and industry level factors that shift investors' preference toward novel or BMC ventures.

Fourth, we collected the data from a single developing country, China, where the venture investment industry is relatively young and is developing fast. While there are many interesting aspects about the Chinese context, such as its relative novelty compared to the traditional US venture capital market, its rapid growth and commensurate importance on a global scale, we acknowledge that the specific characteristics of China's regulatory, normative, and cognitive institutions might have an impact on Chinese investors' evaluation preference. For example, previous research indicates that the unsteady regulatory and normative institutions in China influence the selection of ventures (Bruton \& Ahlstrom, 2003). The government may also have a strong influence on firm goals, while the unique culture discourages entrepreneurs and investors from sharing information with anyone with whom they do not have a close relationship (Bruton \& Ahlstrom, 2003). Institutional inconsistency regarding intellectual property rights is also a noteworthy differentiator (Eesley, Li, \& Yang, 2016) that might lead to lower investors' evaluations compared to similar ventures in different contexts. Further, as China's financial and entrepreneurship environments change and progress with tremendous speed, the rapid development in institutional environments itself might also affect investors' evaluation preference. Future research can investigate the influence of these institutional differences on investors' evaluation of fast follower BMCs and novel ventures. It can also explore the evaluation differences with venture investors in Western markets (such as United States), where investors are relatively more experienced on average than the Chinese investors in our study.

Importantly, as BMCs represent a popular phenomenon in China, one may question whether our findings are generalizable or whether our results depend on Chinese investors' potential biases in the evaluation of fast follower 
BMCs and novel ventures. While we acknowledge the potential influence of the unique institutional environments, we believe the findings are unlikely to result simply from biases for two reasons. First, it is clear from our empirical results that Chinese investors do not particularly prefer fast follower BMCs, since the main effect of the context of fast follower is not significant. Second, the main effect of team major capabilities in exploration on investors' evaluation is positive and significant. This suggests that, in general, Chinese investors are similar to investors in other contexts, in that they are more willing to invest in more innovative teams. Thus, it is unlikely that Chinese investors place more emphasis on skills of imitation and execution than do investors in other contexts.

Fifth, although we tested the influence of investors' individual differences in experience, our work did not capture how other individual differences of investors would affect their evaluation of BMC and novel ventures. For example, we ask investors to assume all else is equal, including the expected return and the relationship between the focal investment and other investments in the investors' portfolios. This means that in our experiment setting, we essentially ask investors to assume the expected returns for investing into a novel venture and a fast follower BMC to be the same (after controlling for the different uncertainty they entail) and to assume that both fast follower BMCs and novel ventures have similar relationships with their portfolios. However, we are unable to test how the general level of expected return (and acceptable uncertainty) of investors and different relationships between the focal investment and other investments in the investors' portfolios would shift their preference toward novel or BMC ventures. Further, our research does not directly capture cognitive factors that potentially affect individual decision making (Shepherd, 2011). In future research, we would like to further investigate how other individual differences might impact investors' evaluation of BMCs and novel ventures.

Finally, as we have three decision-level variables and used a traditional fractional factorial design to reduce the total number of attributes from eight to four, we are unable to test the interaction effects between decision-level factors on investors' evaluation. Although such a limitation causes little harm for investigating our central research question using the current theoretical framework, it means that we are unable to explore other potentially interesting interactions on investors' general evaluation. For example, we are unable to investigate whether the interaction between BM disruptiveness and team exploration-exploitation capabilities has any influence on investors' evaluation of ventures. Thus, in future research, we would like to use a different research design to explore these potentially interesting interactions as well.

Overall, with this work we hope to advance the literature on BMCs, including the conditions under which they are attractive to investors and how investors' experience interacts with these conditions. Clearly, more work remains to be done to catch up to the market realities of BMC investments. We look forward to contributing to and appreciating more forthcoming work in this area.

\section{ACKNOWLEDGEMENTS}

We are especially thankful to Peter Bryant and Julio De Castro for their tireless support during the research process. We are grateful to Dean A. Shepherd, Andrew Corbett, Martina Montauti, Dimo Dimov, and Daniel Clark for their important insights that helped us shape earlier versions of this article. We appreciate the thoughtful comments from the editor, Peter Klein, and two anonymous reviewers who helped us improve and refine this manuscript. We are also grateful to Rongjun Liu and other Chinese venture investors who have supported our research and the data collection process.

\section{REFERENCES}

Adelson, B. (1981). Problem solving and the development of abstract categories in programming languages. Memory \& Cognition, 9(4), 422-433.

Amit, R., \& Zott, C. (2015). Crafting business architecture: The antecedents of business model design. Strategic Entrepreneurship Journal, 9(4), 331-350. 
Bai, Y. (2018). Hangzhou leads the nation in innovation and entrepreneurship, new index says. Retrieved from http://www. zju.edu.cn/english/2018/0402/c19573a811142/page.htm.

Belsley, D. A., Kuh, E., \& Welsch, R. E. (2005). Regression diagnostics: Identifying influential data and sources of collinearity. Hoboken, NJ: John Wiley \& Sons.

Boeker, W. (1989). Strategic change: The effects of founding and history. Academy of Management Journal, 32(3), 489-515.

Brislin, R. W. (1970). Back-translation for cross-cultural research. Journal of Cross-Cultural Psychology, 1(3), 185-216.

Bruton, G. D., \& Ahlstrom, D. (2003). An institutional view of China's venture capital industry: Explaining the differences between China and the west. Journal of Business Venturing, 18(2), 233-259.

Carson, B. (2017). Lyft gets $\$ 1$ billion from Alphabet's investment arm to take on Uber (Vol. 2018). Retrieved from https: //www.forbes.com/sites/bizcarson/2017/10/19/lyft-gets-1-billion-from-alphabets-investment-arm-to-take-onuber/\#f9610bb6b7c8.

Casadesus-Masanell, R. Z. F. (2013). Business model innovation and competitive imitation: The case of sponsor-based business models. Strategic Management Journal, 34(4), 464-482.

Chan, C. S. R., \& Park, H. D. (2015). How images and color in business plans influence venture investment screening decisions. Journal of Business Venturing, 30(5), 732-748.

Chandler, G. N., \& Hanks, S. H. (1994). Market attractiveness, resource-based capabilities, venture strategies, and venture performance. Journal of Business Venturing, 9(4), 331-349.

Chase, W. G., \& Simon, H. A. (1973). Perception in chess. Cognitive Psychology, 4(1), 55-81.

Chen, M.-J. (1996). Competitor analysis and interfirm rivalry: Toward a theoretical integration. Academy of Management Review, 21(1), 100-134.

Choi, Y. R., \& Shepherd, D. A. (2005). Stakeholder perceptions of age and other dimensions of newness. Journal of Management, 31(4), 573-596.

Choo, F., \& Trotman, K. T. (1991). The relationship between knowledge structure and judgments for experienced and inexperienced auditors. Accounting Review, 66(3), 464-485.

Cliff, J. E., Jennings, P. D., \& Greenwood, R. (2006). New to the game and questioning the rules: The experiences and beliefs of founders who start imitative versus innovative firms. Journal of Business Venturing, 21(5), 633-663.

Collis, D. J. (1991). A resource-based analysis of global competition: The case of the bearings industry. Strategic Management Journal, 12(S1), 49-68.

De Rassenfosse, G., \& Fischer, T. (2016). Venture debt financing: Determinants of the lending decision. Strategic Entrepreneurship Journal, 10(3), 235-256.

Dooley, L. M., \& Lindner, J. R. (2003). The handling of nonresponse error. Human Resource Development Quarterly, 14(1), 99-110.

Eesley, C., Li, J. B., \& Yang, D. (2016). Does institutional change in universities influence high-tech entrepreneurship? Evidence from China's project 985. Organization Science, 27(2), 446-461.

Foss, N. J., \& Saebi, T. (2017). Fifteen years of research on business model innovation: How far have we come, and where should we go? Journal of Management, 43(1), 200-227.

Franke, N., Gruber, M., Harhoff, D., \& Henkel, J. (2006). What you are is what you like-Similarity biases in venture capitalists' evaluations of start-up teams. Journal of Business Venturing, 21(6), 802-826.

Franke, N., Gruber, M., Harhoff, D., \& Henkel, J. (2008). Venture capitalists' evaluations of start-up teams: Trade-offs, Knock-out criteria, and the impact of VC experience. Entrepreneurship Theory and Practice, 32(3), 459-483.

Freel, M. S. (2005). Perceived environmental uncertainty and innovation in small firms. Small Business Economics, 25(1), 49-64.

Gagné, R. M., \& Glaser, R. (1987). Foundations in learning research. In R. M. Gagne (Ed.), Instructional Technology: Foundations (pp. 49-83). Hillsdale, NJ: Lawrence Erlbaum Associates.

George, G., \& Bock, A. J. (2011). The business model in practice and its implications for entrepreneurship research. Entrepreneurship Theory and Practice, 35(1), 83-111.

Gobbo, C., \& Chi, M. (1986). How knowledge is structured and used by expert and novice children. Cognitive Development, 1 (3), 221-237.

Green, P. E., \& Srinivasan, V. (1990). Conjoint analysis in marketing: New developments with implications for research and practice. The Journal of Marketing, 54, 3-19.

Gruber, M., Kim, S. M., \& Brinckmann, J. (2015). What is an attractive business opportunity? An empirical study of opportunity evaluation decisions by technologists, managers, and entrepreneurs. Strategic Entrepreneurship Journal, 9(3), 205-225.

Gupta, A. K., Smith, K. G., \& Shalley, C. E. (2006). The interplay between exploration and exploitation. Academy of Management Journal, 49(4), 693-706.

Haynie, J. M., Shepherd, D. A., \& McMullen, J. S. (2009). An opportunity for me? The role of resources in opportunity evaluation decisions. Journal of Management Studies, 46(3), 337-361. 
He, Z.-L., \& Wong, P.-K. (2004). Exploration vs. exploitation: An empirical test of the ambidexterity hypothesis. Organization Science, 15(4), 481-494.

Janney, J. J., \& Folta, T. B. (2003). Signaling through private equity placements and its impact on the valuation of biotechnology firms. Journal of Business Venturing, 18(3), 361-380.

Kim, L. (1997). Imitation to innovation: The dynamics of Korea's technological learning. Boston, MA: Harvard Business Press.

Klotz, A. C., Hmieleski, K. M., Bradley, B. H., \& Busenitz, L. W. (2014). New venture teams a review of the literature and roadmap for future research. Journal of Management, 40(1), 226-255.

Kollmann, T., \& Kuckertz, A. (2010). Evaluation uncertainty of venture capitalists' investment criteria. Journal of Business Research, 63(7), 741-747.

Li, Y. (2008). Duration analysis of venture capital staging: A real options perspective. Journal of Business Venturing, 23(5), 497-512.

Lieberman, M. B., \& Asaba, S. (2006). Why do firms imitate each other? Academy of Management Review, 31(2), 366-385.

Lieberman, M. B., \& Montgomery, D. B. (1988). First-Mover Advantages. Strategic Management Journal, 9, 41-58.

Lieberman, M. B., \& Montgomery, D. B. (1998). First-mover (dis)advantages: Retrospective and link with the resource-based view. Strategic Management Journal, 19(12), 1111-1125.

Lohrke, F. T., Holloway, B. B., \& Woolley, T. W. (2010). Conjoint analysis in entrepreneurship research a review and research agenda. Organizational Research Methods, 13(1), 16-30.

MacMillan, I. C., Siegel, R., \& Narasimha, P. N. S. (1985). Criteria used by venture capitalists to evaluate new venture proposals. Journal of Business Venturing, 1(1), 119-128.

March, J. G. (1991). Exploration and exploitation in organizational learning. Organization Science, 2(1), 71-87.

Maxwell, A. L., Jeffrey, S. A., \& Lévesque, M. (2011). Business angel early stage decision making. Journal of Business Venturing, 26(2), 212-225.

McKelvie, A., Haynie, J. M., \& Gustavsson, V. (2011). Unpacking the uncertainty construct: Implications for entrepreneurial action. Journal of Business Venturing, 26(3), 273-292.

McMullen, J. S., \& Shepherd, D. A. (2006). Entrepreneurial action and the role of uncertainty in the theory of the entrepreneur. Academy of Management Review, 31(1), 132-152.

Miller, S. R., Indro, D. C., Richards, M., \& Chng, D. H. M. (2013). Financial implications of local and nonlocal rival isomorphism: A signaling paradox. Journal of Management, 39(7), 1979-2008.

Milliken, F. J. (1987). Three types of perceived uncertainty about the environment: State, effect, and response uncertainty. Academy of Management Review, 12(1), 133-143.

Mitchell, J. R., \& Shepherd, D. A. (2010). To thine own self be true: Images of self, images of opportunity, and entrepreneurial action. Journal of Business Venturing, 25(1), 138-154.

Mitteness, C., Sudek, R., \& Cardon, M. S. (2012). Angel investor characteristics that determine whether perceived passion leads to higher evaluations of funding potential. Journal of Business Venturing, 27(5), 592-606.

Murnieks, C. Y., Cardon, M. S., Sudek, R., White, T. D., \& Brooks, W. T. (2016). Drawn to the fire: The role of passion, tenacity and inspirational leadership in angel investing. Journal of Business Venturing, 31(4), 468-484.

Murnieks, C. Y., Haynie, J. M., Wiltbank, R. E., \& Harting, T. (2011). 'I like how you think': Similarity as an interaction bias in the investor-entrepreneur dyad. Journal of Management Studies, 48(7), 1533-1561.

Muzyka, D., Birley, S., \& Leleux, B. (1996). Trade-offs in the investment decisons of European venture capitalists. Journal of Business Venturing, 11(4), 273-287.

Nachtsheim, C. J., Neter, J., Kutner, M. H., \& Wasserman, W. (2004). Applied linear regression models. Boston, MA: McGrawHill Irwin.

Packard, M. D., Clark, B. B., \& Klein, P. G. (2017). Uncertainty types and transitions in the entrepreneurial process. Organization Science, 28(5), 840-856.

Petty, J. S., \& Gruber, M. (2011). "In pursuit of the real deal": A longitudinal study of VC decision making. Journal of Business Venturing, 26(2), 172-188.

Raisch, S., Birkinshaw, J., Probst, G., \& Tushman, M. L. (2009). Organizational ambidexterity: Balancing exploitation and exploration for sustained performance. Organization Science, 20(4), 685-695.

Rivkin, J. W. (2000). Imitation of complex strategies. Management Science, 46(6), 824-844.

Rivkin, J. W. (2001). Reproducing knowledge: Replication without imitation at moderate complexity. Organization Science, 12(3), 274-293.

Samuelsson, M., \& Davidsson, P. (2009). Does venture opportunity variation matter? Investigating systematic process differences between innovative and imitative new ventures. Small Business Economics, 33(2), 229-255.

Shepherd, D. A. (1999a). Venture capitalists' assessment of new venture survival. Management Science, 45(5), 621-632.

Shepherd, D. A. (1999b). Venture capitalists' introspection: A comparison of "in use" and "espoused" decision policies. Journal of Small Business Management, 37(2), 76. 
Shepherd, D. A. (2011). Multilevel entrepreneurship research: Opportunities for studying entrepreneurial decision making. Journal of Management, 37(2), 412-420.

Shepherd, D. A., Ettenson, R., \& Crouch, A. (2000). New venture strategy and profitability: A venture capitalist's assessment. Journal of Business Venturing, 15(5), 449-467.

Shepherd, D. A., Patzelt, H., \& Baron, R. A. (2013). "I care about nature, but...": Disengaging values in assessing opportunities that cause harm. Academy of Management Journal, 56(5), 1251-1273.

Shepherd, D. A., \& Zacharakis, A. (1999). Conjoint analysis: A new methodological approach for researching the decision policies of venture capitalists. Venture Capital: An International Journal of Entrepreneurial Finance, 1(3), $197-217$.

Shepherd, D. A., Zacharakis, A., \& Baron, R. A. (2003). VCs' decision processes: Evidence suggesting more experience may not always be better. Journal of Business Venturing, 18(3), 381-401.

Smith, W. K., Binns, A., \& Tushman, M. L. (2010). Complex business models: Managing strategic paradoxes simultaneously. Long Range Planning, 43(2), 448-461.

Spence, M. T., \& Brucks, M. (1997). The moderating effects of problem characteristics on experts' and novices' judgments. Journal of Marketing Research, 34(2), 233-247.

Suarez, F. F., Grodal, S., \& Gotsopoulos, A. (2015). Perfect timing? Dominant category, dominant design, and the window of opportunity for firm entry. Strategic Management Journal, 36(3), 437-448.

Suarez, F. F., \& Lanzolla, G. (2007). The role of environmental dynamics in building a first mover advantage theory. Academy of Management Review, 32(2), 377-392.

Teece, D. J. (1986). Profiting from technological innovation: Implications for integration, collaboration, licensing and public policy. Research Policy, 15(6), 285-305.

Ulhøi, J. P. (2012). Modes and orders of market entry: Revisiting innovation and imitation strategies. Technology Analysis \& Strategic Management, 24(1), 37-50.

Valliere, D., \& Peterson, R. (2004). Inflating the bubble: Examining dot-com investor behaviour. Venture Capital, 6(1), 1-22.

Voss, G. B., \& Voss, Z. G. (2013). Strategic ambidexterity in small and medium-sized enterprises: Implementing exploration and exploitation in product and market domains. Organization Science, 24(5), 1459-1477.

Warnick, B. J., Murnieks, C. Y., McMullen, J. S., \& Brooks, W. T. (2018). Passion for entrepreneurship or passion for the product? A conjoint analysis of angel and VC decision-making. Journal of Business Venturing, 33(3), 315-332.

Wei, N. S. (2018). Foodpanda ready for 'burn war' as GrabFood enters fray, Vol. March 6th 2019. Retrieved from https: //www.sgsme.sg/news/startups/foodpanda-ready-burn-war-grabfood-enters-fray.

Weill, P., Malone, T. W., \& Apel, T. G. (2011). The business models investors prefer. MIT Sloan Management Review, 52(4), 17.

Wiklund, J., Baker, T., \& Shepherd, D. (2010). The age-effect of financial indicators as buffers against the liability of newness. Journal of Business Venturing, 25(4), 423-437.

Winter, S. G., \& Szulanski, G. (2001). Replication as strategy. Organization Science, 12(6), 730-743.

Wood, M. S., McKelvie, A., \& Haynie, J. M. (2014). Making it personal: Opportunity individuation and the shaping of opportunity beliefs. Journal of Business Venturing, 29(2), 252-272.

Yang, Y. (2018). Bike sharing in China: Ofo, Mobike and the lure of two wheels, Vol. 2018. Retrieved from https://www.ft. com/content/891bdf44-26db-11e8-b27e-cc62a39d57a0.

York, J. G., \& Venkataraman, S. (2010). The entrepreneur-environment nexus: Uncertainty, innovation, and allocation. Journal of Business Venturing, 25(5), 449-463.

Zacharakis, A. L., \& Shepherd, D. A. (2001). The nature of information and overconfidence on venture capitalists' decision making. Journal of Business Venturing, 16(4), 311-332.

Zachary, M. A., Gianiodis, P. T., Payne, G. T., \& Markman, G. D. (2015). Entry timing: Enduring lessons and future directions. Journal of Management, 41(5), 1388-1415.

Zaleski, A. (2017). 7 businesses that cloned others and made millions, Vol. March 29th 2018. Retrieved from https://www. cnbc.com/2017/10/03/7-businesses-that-cloned-others-and-made-millions.html.

Zott, C., \& Amit, R. (2007). Business model design and the performance of entrepreneurial firms. Organization Science, 18(2), $181-199$.

Zott, C., Amit, R., \& Massa, L. (2011). The business model: Recent developments and future research. Journal of Management, 37(4), 1019-1042.

Zott, C., \& Huy, Q. N. (2007). How entrepreneurs use symbolic management to acquire resources. Administrative Science Quarterly, 52(1), 70-105.

How to cite this article: Fu Y, Tietz MA. When do investors prefer copycats? Conditions influencing the evaluation of innovative and imitative ventures. Strategic Entrepreneurship Journal. 2019;13:529-551.

https://doi.org/10.1002/sej.1338 